\title{
Physical Activity and Menstrual Disorders Among School Girls in Southern Egypt
}

\author{
Hanan Elzeblawy Hassan ${ }^{1}$, Walaa Fathy Mohamed Ahmed ${ }^{2} \&$ Ahmed Arafa ${ }^{3}$ \\ ${ }^{1}$ Department of Maternal and Newborn Health Nursing, Faculty of Nursing, Beni-Suef University, Egypt \\ ${ }^{2}$ Department of Maternity and Gynecological Nursing, Faculty of Nursing, Ain Shams University, Egypt \\ ${ }^{3}$ Department of Public Health, Faculty of Medicine, Beni-Suef University, Egypt \\ Correspondence: Hanan Elzeblawy Hassan, Maternal and Newborn Health Nursing, Faculty of Nursing, \\ Beni-Suef University, Egypt. E-mail: nona_nano_1712@yahoo.com
}

Received: July 7, 2019

Accepted: July 23, 2019

Online Published: July 31, 2019

doi:10.20849/ijsn.v4i3.614

URL: https://doi.org/10.20849/ijsn.v4i3.614

\begin{abstract}
Introduction: Menstrual disorders are the most frequent gynecological diagnoses among young girls.

Aim: This study was conducted to investigate whether physical activity could reduce menstrual disorders among schoolgirls.
\end{abstract}

Methods: In this cross-sectional study, 970 schoolgirls in Southern Egypt were assessed, using a questionnaire, for their socio-demographic characteristics, gynecological history, physical activity, and menstrual disorders during the previous 6 months.

Results: The mean age of schoolgirls was $15.5 \pm 0.8$ years, menarche age $13.2 \pm 1.2$ years, menstrual cycle duration $28.8 \pm 7.3$ days, and $76.1 \%$ were circumcised. After adjustment for the socio-demographic and gynecological variables, physical activity was shown to be not associated with all premenstrual symptoms and dysmenorrhea ( $\mathrm{p}$-value $>0.05$ ).

Conclusion: No substantial associations between physical activities and menstrual/premenstrualal symptoms can be concluded.

Recommendations: Future cohort and interventional studies are needed to explain whether the risk of dysmenorrhea and premenstrual symptoms can be reduced by physical activity.

Keywords: dysmenorrhea, physical activity, premenstrual disorders, schoolgirls

\section{Introduction}

Menstrual disorders are common concerns among adolescents since these symptoms carry several debilitating impacts on their physical, emotional, educational, and social well-being [1,2]. The additional healthcare costs, sick leaves, and academic shortcomings attributed to menstrual disorders add an enormous economic burden on the adolescents, their families, and health care systems [3].

Several risk factors such as stress, smoking, hormonal disturbances, and unhealthy dietary behaviors are thought to increase the risk of menstrual disorders [2,4,5]. Theoretically, physical activity may protect from menstrual disturbances. It can optimize the levels of corticotropin-releasing hormone, cortisol, prolactin, thyroid hormones, endorphins, and prostaglandins. These hormones and hormone-like compounds play a pivotal role in regulating the menstrual cycle and their disturbance can lead to menstrual disorders [6-8]. Although significant emotional and physical menstrual symptoms were detected among the physically inactive women [9-10], some studies denied any association between physical activities and menstrual irregularities [11-13].

\subsection{Operational Definitions}

Researchers defined the premenstrual symptoms as physical and emotional symptoms experienced within 7-10 days before menstruation. These symptoms included spasm, fatigue, headache, irritation and/or nervousness, breast tenderness, insomnia, nausea and/or vomiting, and abdominal bloating. Also, we defined menstrual symptoms as symptoms experienced during the flow days and included flow days, dysmenorrhea, acne flare, dysuria, and facial hair. To avoid misclassification bias, dysmenorrhea was defined as a state of painful cramping 
sensation hitting the groin during flow days [14]. The severity of dysmenorrhea was determined according to its duration, using medications, and school absenteeism.

\subsection{Aim of the Study}

Nevertheless, there is a scarcity in the population-based studies investigating the association between physical activity and premenstrual and menstrual symptoms. Besides, the available literature inspected women with a long history of menstrual disorders rather than adolescents, described the menstrual disorders collectively without details, and did not adjust the findings for potential socio-demographic and gynecological characteristics. We, therefore, conducted this study to investigate these associations among school girls in Southern Egypt.

\subsection{Research Questions}

What is the prevalence of physical activity among schoolgirls in Southern Egypt 6 months ago?

What are the types of premenstrual and menstrual symptoms among schoolgirls in Southern Egypt 6 months ago?

Is there association between physical inactivity and premenstrual and menstrual symptoms among schoolgirls in Southern Egypt?

\section{Subjects and Methods}

\subsection{Study Design and Settings}

In this the cross-sectional study, the researchers included schoolgirls from 4 public preparatory schools in Beni-Suef City, in Southern Egypt, during the period between $1^{\text {st }}$ January to $30^{\text {th }}$ April 2019.

\subsection{Sampling Procedures}

The sample size was determined using the Epi-Info version 7 Stat Calc, [Center for Disease Control (CDC), World Health Organization (WHO)] using the following criteria: a confidence level of $95.0 \%$ and a margin of error of $5.0 \%$. The least sample size was 381 ; however, it was tripled to enhance the statistical power. To select our sample population, we divided Beni-Suef City geographically into 4 areas and 1 school was randomly selected from each area by card withdrawal. All schoolgirls in the checklists of the 4 schools were invited to participate in the study. Schoolgirls enrolled for evening classes and those who were absent during the interview day were excluded from the study.

\subsection{Data Collecting Tool}

The researchers prepared an Arabic questionnaire comprised of 4 sections. The first section included socio-demographic questions; age, residence, education of parents, sleeping hours, exposure to passive smoking, and preference for salty-fatty food. The second section included gynecological history questions; circumcision, the age of the first menarche, days of menstrual flow, and menstrual cycle duration. The third section included questions about premenstrual and menstrual symptoms during the previous 6 months. The fourth section assessed the physical activity using the Global Physical Activity Questionnaire which encompassed 2 questions about the duration of physical activity in the form of days/week and hours/day. This short questionnaire is typically used to identify whether an individual meets a physical activity standard [15].

\section{Validity and Readability of Tool}

The Cronbach's alpha for the reliability was 0.85 and the content validity was judged by professors of and professors of maternity, gynecology \& obstetrics and public health professors from the faculties of Medicine and Nursing, Beni-Suef University as well as faculties of Nursing, Ain Shams University.

\section{Research's Ethical Considerations}

The study protocol was approved by Beni-Suef University Research Ethics Committee. Then, the heads of the selected schools were contacted for institutional approvals and they signed informed consent forms on behalf of the schoolgirls after being briefed on the steps and aims of the study. Girls were required to give their verbal assent before participation.

\section{Pilot Study}

Researchers conducted a pilot study on 97 students to assure adequacy and clarity of the designed questionnaire.

\section{Statistical Analyses}

Researchers used the software, Statistical Package for Social Science (SPSS Inc. Released 2009, PASW Statistics for Windows, version 18.0: SPSS Inc., Chicago, Illinois, USA) for statistical analysis. As suggested by Coleman et al, schoolgirls who reported less than 150 minutes/week of moderate to vigorous physical activity were classified 
physically inactive [15]. Multivariable regression analyses were done to determine whether physical activity was related to specific premenstrual and menstrual disorders. The following covariates were included in the regression models; age, parental education, passive smoking, diet, sleeping hours, circumcision, and age of menarche.

Description of quantitative variables were presented as mean and SD (Mean \pm SD)

A confidence level (CI) was considered as $95 \%$

Probability ( $\mathrm{p}$-value) was considered as follows:

$P$ value $>0.05$ insignificant

$* \mathrm{P}<0.05$ mild significant correlation

$* * \mathrm{P}<0.01$ moderate significant correlation

$* * * \mathrm{P}<0.001$ highly significant correlation

\section{Results}

With 970 participating schoolgirls, the physical activity represented $16.3 \%$, while $83.7 \%$ of the participants were inactive (Figure 1).

The mean age of the participating schoolgirls was $15.5 \pm 0.8$ years, menarche age $13.2 \pm 1.2$ years, menstrual cycle duration $28.8 \pm 7.3$ days; flow days $5.0 \pm 1.3$, and $76.1 \%$ were circumcised. Schoolgirls with educated parents and older age of menarche were more likely to report physical activity (Table 1).

While premenstrual spasm and fatigue were the most commonly reported premenstrual symptoms, dysmenorrhea was heavily reported during flow days. Using univariate analysis, physical activity associated with irritation and nervousness (OR: 1.5, 95\% CI: 1-2.2, p-value=0.043) and abdominal bloating (OR: 1.9, 95\% CI: 1.1-3.4, p-value $=0.024)$. After adjustment for the covariates, none of these associations remained significant. Physical activity did not associate with dysmenorrhea or any of the investigated premenstrual symptoms ( $p$-value $>0.05)($ Table 2$)$.

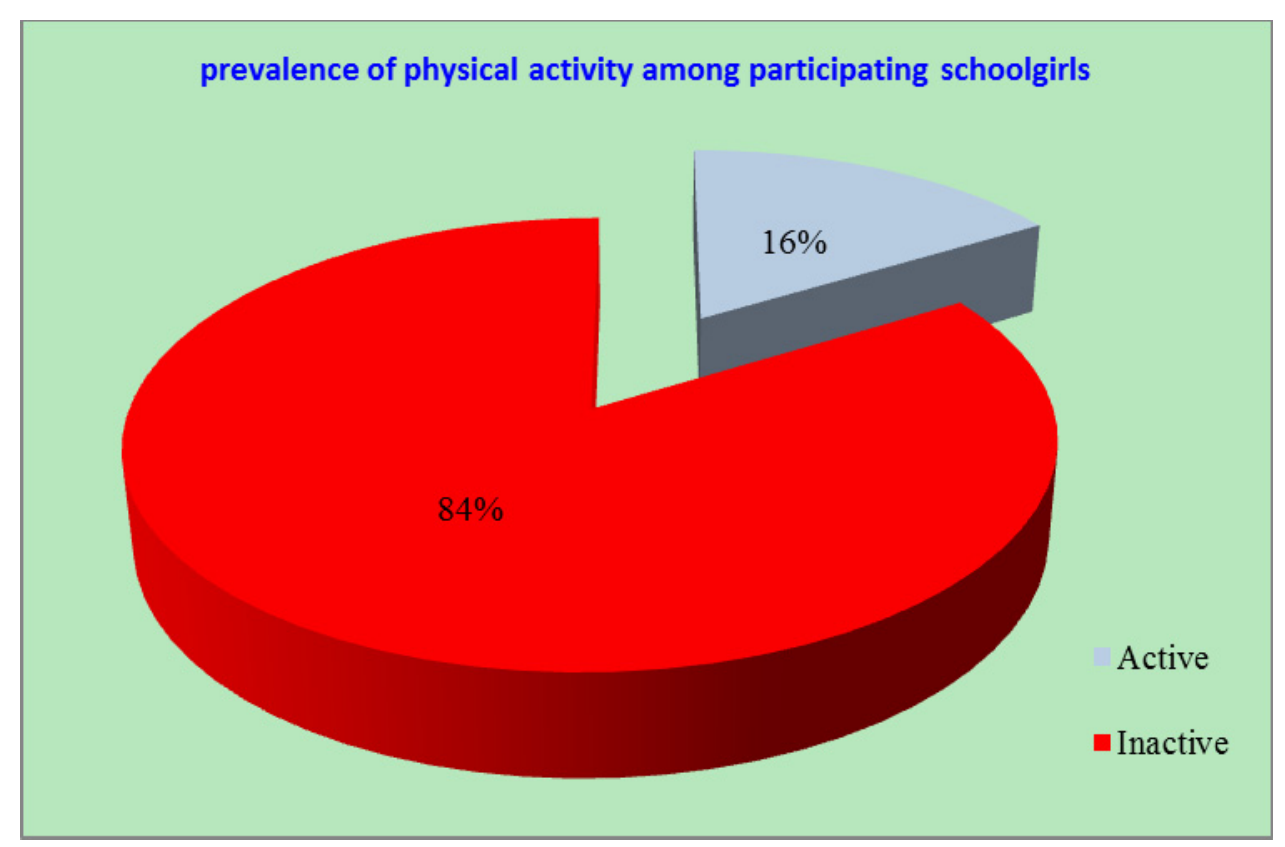

Figure 1. Prevalence of physical activity among participating schoolgirls 
Table 1. Socio-demographic, life style, and gynecological characteristics of the participating schoolgirls $(n=970)$ according to their physical activity

\begin{tabular}{|c|c|c|c|c|c|}
\hline \multicolumn{2}{|l|}{ Characteristics } & Active, $\mathrm{n}=158$ & Inactive, $\mathrm{n}=812$ & Total & P-value \\
\hline \multicolumn{2}{|l|}{ Age years; Mean $\pm \mathrm{Sd}$} & $15.66 \pm 0.70$ & $15.51 \pm 0.84$ & $15.54 \pm 0.82$ & 0.041 \\
\hline \multirow{2}{*}{ Father's Education } & Illiterate & $24(15.2)$ & $238(29.3)$ & $262(27.0)$ & \multirow{2}{*}{$<0.001 * * *$} \\
\hline & Literate & $134(84.8)$ & $574(70.7)$ & $708(73.0)$ & \\
\hline \multirow{2}{*}{ Mother's Education } & Illiterate & $41(25.9)$ & $378(46.6)$ & $419(43.2)$ & \multirow{2}{*}{$<0.001 * * *$} \\
\hline & Literate & $117(74.1)$ & $434(53.4)$ & $434(53.4)$ & \\
\hline \multirow{2}{*}{ Passive Smoking } & Yes & $85(53.8)$ & $409(50.4)$ & $494(50.9)$ & \multirow{2}{*}{0.242} \\
\hline & No & $73(46.2)$ & $403(49.6)$ & $476(49.1)$ & \\
\hline \multirow{2}{*}{$\begin{array}{l}\text { Preference of Salty } \\
\text { Diets }\end{array}$} & Yes & $130(82.3)$ & $576(70.9)$ & $706(72.8)$ & \multirow{2}{*}{$0.002 * *$} \\
\hline & No & $28(17.7)$ & $236(29.1)$ & $264(27.2)$ & \\
\hline \multirow{2}{*}{ Circumcision } & Yes & $113(71.5)$ & $625(77.0)$ & $738(76.1)$ & \multirow{2}{*}{0.087} \\
\hline & No & $45(28.5)$ & $187(23.0)$ & $232(23.9)$ & \\
\hline \multicolumn{2}{|c|}{ Sleeping Hours/day; Mean \pm SD } & $8.63 \pm 2.28$ & $8.66 \pm 1.88$ & $8.66 \pm 1.94$ & 0.865 \\
\hline \multicolumn{2}{|c|}{ Menarche Age years; Mean \pm SD } & $13.45 \pm 1.28$ & $13.15 \pm 1.16$ & $13.20 \pm 1.19$ & $0.004 * *$ \\
\hline \multicolumn{2}{|c|}{$\begin{array}{l}\text { Menstrual Cycle Duration days; Mean } \\
\pm \mathrm{SD}\end{array}$} & $28.36 \pm 5.59$ & $28.90 \pm 7.63$ & $28.81 \pm 7.33$ & 0.402 \\
\hline \multicolumn{2}{|c|}{$\begin{array}{l}\text { Menstrual Flow Duration days; Mean } \pm \\
\text { SD }\end{array}$} & $5.07 \pm 1.27$ & $5.02 \pm 1.32$ & $5.03 \pm 1.32$ & 0.663 \\
\hline
\end{tabular}

Table 2. Crude and multi-variable adjusted odds ratios and confidence intervals of the menstrual symptoms during the previous 6 months among the participating schoolgirls $(n=970)$ according to their physical activity

\begin{tabular}{|c|c|c|c|c|c|c|}
\hline Menstrual Symptoms & Active & $\begin{array}{l}\text { Inactive } \\
\text { (Ref) }\end{array}$ & $\begin{array}{c}\text { Crude } \\
\text { P-value }\end{array}$ & $\begin{array}{l}\text { Crude OR } \\
(95 \% \mathrm{CI})\end{array}$ & $\begin{array}{l}\text { Adjusted } \\
\text { P-value }\end{array}$ & $\begin{array}{c}\text { Adjusted } \\
\text { OR }(95 \% \mathrm{CI})\end{array}$ \\
\hline $\begin{array}{l}\text { Menstrual Cycle }>28 \\
\text { days }\end{array}$ & $70(44.3)$ & $312(38.4)$ & 0.098 & $1.3(0.9-1.8)$ & 0.526 & $1.1(0.8-1.6)$ \\
\hline \multicolumn{7}{|l|}{ Premenstrual } \\
\hline Spasm & $99(62.7)$ & $503(61.9)$ & 0.470 & $1.0(0.7-1.5)$ & 0.973 & $1.0(0.7-1.4)$ \\
\hline Headache & $36(22.8)$ & $178(21.9)$ & 0.441 & $1.1(0.7-1.6)$ & 0.686 & $1.1(0.7-1.7)$ \\
\hline Irritation/Nervousness & $38(24.1)$ & $144(17.7)$ & 0.043 & $1.5(1.0-2.2)$ & 0.102 & $1.4(0.9-2.2)$ \\
\hline Breast Tenderness & $22(13.9)$ & $132(16.3)$ & 0.273 & $0.8(0.5-1.4)$ & 0.449 & $0.8(0.5-1.4)$ \\
\hline Insomnia & $26(16.5)$ & $110(13.5)$ & 0.199 & $1.3(0.8-2.0)$ & 0.605 & $1.1(0.7-1.8)$ \\
\hline Nausea/Vomiting & $15(9.5)$ & $77(9.5)$ & 0.547 & $1.0(0.6-1.8)$ & 0.623 & $0.9(0.5-1.6)$ \\
\hline Abdominal Bloating & $17(10.8)$ & $48(5.9)$ & $0.024^{*}$ & $1.9(1.1-3.4)$ & 0.051 & $1.8(1.0-3.3)$ \\
\hline \multicolumn{7}{|l|}{ Menstrual } \\
\hline Flow days $>4$ days & $101(63.9)$ & $524(64.5)$ & 0.476 & $1.0(0.7-1.4)$ & 0.747 & $0.9(0.7-1.4)$ \\
\hline Dysmenorrhea & $147(93.0)$ & $718(88.4)$ & 0.053 & $1.7(0.9-3.3)$ & 0.112 & $1.8(0.9-3.3)$ \\
\hline Dysmenorrhea $>1$ day & $105(71.4)$ & $461(64.2)$ & 0.056 & $1.4(0.9-2.1)$ & 0.339 & $1.2(0.8-1.8)$ \\
\hline $\begin{array}{l}\text { Dysmenorrhea With } \\
\text { Medications }\end{array}$ & $68(46.3)$ & $336(46.8)$ & 0.489 & $1.0(0.7-1.4)$ & 0.762 & $0.9(0.6-1.4)$ \\
\hline $\begin{array}{l}\text { Dysmenorrhea With } \\
\text { Absenteeism }\end{array}$ & $69(46.9)$ & $339(47.2)$ & 0.512 & $1.0(0.7-1.4)$ & 0.570 & $0.9(0.6-1.3)$ \\
\hline Acne Flare & $54(34.2)$ & $248(30.5)$ & 0.208 & $1.2(0.8-1.7)$ & 0.685 & $1.1(0.7-1.6)$ \\
\hline Dysuria & $18(11.4)$ & $99(12.2)$ & 0.450 & $0.9(0.5-1.6)$ & 0.785 & $0.9(0.5-1.6)$ \\
\hline Facial Hair & $7(4.4)$ & $30(3.7)$ & 0.397 & $1.2(0.5-2.8)$ & 0.562 & $1.3(0.5-3.1)$ \\
\hline
\end{tabular}




\section{Discussion}

This study detected no evidence of a substantial relationship between physical activities and menstrual disorders. Although physical activity increases the endorphin levels, suppresses the release of prostaglandins, improves the oxygen in muscles, and reduces sex hormones and cortisol, its association with menstrual disorders remains inconclusive $[6,7,16]$.

One explanation for our findings is that the mean age of schoolgirls was 15.5 years while their mean age of menarche was 13.2 years. The majority of cycles in the first two years are anovulatory, and often not associated with progestin/prostaglandin mediated dysmenorrhea associated with anovulation [17].

Further, it should be noted that the previous studies which investigated the same association used different study methods and statistical approaches, adopted different definitions for physical activity, and included populations with different socio-demographic characteristics. These variations led to remarkable inconsistencies in the findings across the studies and made the comparisons quite difficult. For example, the definition of physical activities in the cross-sectional study was practicing moderate to vigorous physical activities for 150 minutes/week. On the other hand, Aganoff and Boyle used a stricter definition of physical activity. They recruited women from fitness clubs after the end of their aerobic sessions to represent the physically active and compared them to apparently healthy women who denied practicing sport. Yet, the authors detected only negative mood not physical symptoms among the physically inactive [9]. Using a cross-sectional design, Vani et al concluded that adolescents who reported physical activity for more than 3 days/week, regardless of training hours per day, had less premenstrual syndrome but the same dysmenorrhea [10]. Johnson et al used a prospective approach to explore the same association and concluded that the days of training correlated negatively with some premenstrual symptoms [18]. In their clinical trial, El-Lithy and colleagues found that training 3 times/week for 3 months led to a significant improvement in all premenstrual symptoms [19].

Although estimating the prevalence of menstrual disorders among schoolgirls is beyond the aim of this study, the researcher noticed that most school girls experienced dysmenorrhea during the previous 6 months and this dysmenorrhea was severe enough to require medication and school absenteeism. They also reported high rates of premenstrual symptoms, especially spasm and/or fatigue. This refers to the crucially of studying the factors that predispose to menstrual disorders with the purpose of creating risk-prevention strategies to reduce their incidence and minimize their negative effects.

\section{Limitations of the Study}

This study described the association between physical activity and most premenstrual and menstrual disorders after adjustment for socio-demographic and gynecologic factors, yet some limitations should be considered. The first, some covariates that can affect the occurrence of menstrual disorders such as body mass index (BMI) and family history of menstrual disorders were not included in the survey. Besides, pain is very subjective to a given individual diagnosis of dysmenorrhea and its severity cannot be confirmed.

\section{Conclusion and Recommendations}

Premenstrual spasm and fatigue were the most commonly reported premenstrual symptoms; dysmenorrhea was heavily reported during flow days. Physical activity associated with irritation, nervousness and abdominal bloating. In conclusion, we could not reach a robust conclusion that physical activity could protect from menstrual disorders.

\section{Recommendations}

Physical activity is highly recommended for schoolgirls.

Future cohort and interventional studies are needed to explain whether the risk of dysmenorrhea and premenstrual symptoms can be reduced by physical activity.

Conflict of Interest: None.

Funding: None.

\section{References}

[1] Knox, B., Azurah, A., \& Grover, S. (2015). Quality of life and menstruation in adolescents. Curr Opin Obstet Gynecol, 27(5), 309-314. https://doi.org/10.1097/GCO.0000000000000199

[2] Hailemeskel, S., Demissie, A., \& Assefa, N. (2016). Primary dysmenorrhea magnitude, associated risk factors, and its effect on academic performance: Evidence from female university students in Ethiopia. Int $J$ Womens Health, 8, 489-496. https://doi.org/10.2147/IJWH.S112768 
[3] Tanaka, E., Momoeda, M., Osuga, Y., Rossi, B., Nomoto, K., ... Hayakawa, M. (2014). Burden of menstrual symptoms in Japanese women; An analysis of medical care-seeking behavior from a survey-based study. Int $J$ Womens Health, 6, 11-23. https://doi.org/10.2147/IJWH.S52429

[4] Ju, M., Jones, M., \& Mishra, G. (2014). The prevalence and risk factors of dysmenorrhea. Epid Rev, 36(1), 104-13. https://doi.org/10.1093/epirev/mxt009

[5] Emem, E., \& Hassan, H. (2017). Correlation between Quality of Life and Dysmenorrhea among Nursing Schools Students. International Journal of Nursing Science, 7(6), 123-132. https://doi.org/10.5923/j.nursing.20170706.02

[6] Cho, G., Han, S., Shin, J., \& Kim, T. (2017). Effects of intensive training on menstrual function and certain serum hormones and peptides related to the female reproductive system. Medicine (Baltimore), 96(21), e6876. https://doi.org/10.1097/MD.0000000000006876

[7] Trappe, T., \& Liu, S. (2013). Effects of prostaglandins and COX-inhibiting drugs on skeletal muscle adaptations to exercise. $J$ Appl Physiol, 115(6), 909-919. https://doi.org/10.1152/japplphysiol.00061.2013

[8] Hassan, H., Gamel, W., Sheha, E., Sayed, M., \& Arafa, A. (2019). Menstrual disorders necessitating counseling among students in Beni-Suef University. Clinical Nursing Studies, 7(2), 29-36. https://doi.org/10.5430/cns.v7n2p29

[9] Aganoff, J., \& Boyle, G. (1994). Aerobic exercise, mood states and menstrual cycle symptoms. J Psychosom Res, 38(3), 183-192. https://doi.org/10.1016/0022-3999(94)90114-7

[10] Vani, K., Veena, K., Subitha, L., Kumar, V., \& Bupathy, A. (2013). Menstrual abnormalities in school going girls - Are they related to dietary and exercise pattern?. J Clin Diagn Res, 7(11), 2537-2540.

[11] Blakey, H., Chisholm, C., Dear, F., Harris, B., Hartwell, R., ... Daley, A. (2010). Is exercise associated with primary dysmenorrhoea in young women?. Obestet Gynecol, 117 (2), 222-224. https://doi.org/10.1111/j.1471-0528.2009.02220.x

[12] Kroll-Desrosiers, A., Ronnenberg, A., Zagarins, S., Houghton, S., Takashima-Uebelhoer, B., \& Bertone-Johnson, E. (2017). Recreational physical activity and premenstrual syndrome in young adult women: A cross-sectional study. PLoS One, 12(1), e0169728. https://doi.org/10.1371/journal.pone.0169728

[13] Arafa, A., Khamis, Y., Hassan, H., Saber, N., \& Abbas, A. (2018). Epidemiology of dysmenorrhea among workers in Upper Egypt; A cross sectional study. Middle East Fertil Soc J., 23, 44-47. https://doi.org/10.1016/j.mefs.2017.07.002

[14] French, L. (2005). Dysmenorrhea. Am Fam Physician, 71(2), 285-291.

[15] Coleman, K., Ngor, E., Reynolds, K., Quinn, V., Koebnick, C., .. Young, D. (2012). Initial validation of an exercise "vital sign" in electronic medical records. Med Sci Sports Exerc, 44, 2071-2076. https://doi.org/10.1249/MSS.0b013e3182630ec1

[16] Schwarz, L., \& Kindermann, W. (1992). Changes in beta-endorphin levels in response to aerobic and anaerobic exercise. Sports Med, 13(1), 25-36. https://doi.org/10.2165/00007256-199213010-00003

[17] Rosenfield, R. L. (2013). Clinical review: Adolescent anovulation: maturational mechanisms and implications. J Clin Endocrinol Metab, 98(9), 3572-3583. https://doi.org/10.1210/jc.2013-1770

[18] Johnson, W., Carr-Nangle, R., \& Bergeron, K. (1995). Macronutrient intake, eating habits, and exercise as moderators of menstrual distress in healthy women. Psychosom Med, 57, 324-330. https://doi.org/10.1097/00006842-199507000-00003

[19] El-Lithy, A., El-Mazny, A., Sabbour, A., \& El-Deeb, A. (2015). Effect of aerobic exercise on premenstrual symptoms, haematological and hormonal parameters in young women. J Obstet Gynaecol, 35(4), 389-392. https://doi.org/10.3109/01443615.2014.960823

\section{Copyrights}

Copyright for this article is retained by the author(s), with first publication rights granted to the journal.

This is an open-access article distributed under the terms and conditions of the Creative Commons Attribution license (http://creativecommons.org/licenses/by/4.0/). 